\title{
The Advantages and Disadvantages of Physical Exercise among Future Engineers and Technologists
}

\author{
Mohd Firdaus Abdullah, ${ }^{1,2, *}$, Asiah Mohd Pilus ${ }^{1}$, Mohd Radzani Abdul Razak², \\ Abu Yazid Abu Bakar², Denise Koh Choon Lian², Mohamad Nizam Nazarudin ${ }^{3}$ \\ ${ }^{1}$ Institute of Technology Management and Entrepreneurship, Universiti Teknikal Malaysia Melaka, 76100 Melaka, Malaysia \\ ${ }^{2}$ Faculty of Education, Universiti Kebangsaan Malaysia, 43600 Bangi, Selangor, Malaysia \\ ${ }^{3}$ Faculty of Psychology and Education, Universiti Malaysia Sabah, 88400 Kota Kinabalu, Sabah, Malaysia
}

Received January 16, 2021; Revised March 2, 2021; Accepted March 23, 2021

\section{Cite This Paper in the following Citation Styles}

(a): [1] Mohd Firdaus Abdullah, Asiah Mohd Pilus, Mohd Radzani Abdul Razak, Abu Yazid Abu Bakar, Denise Koh Choon Lian, Mohamad Nizam Nazarudin, "The Advantages and Disadvantages of Physical Exercise among Future Engineers and Technologists," International Journal of Human Movement and Sports Sciences, Vol. 9, No. 2, pp. 340 346, 2021. DOI: 10.13189/saj.2021.090223.

(b): Mohd Firdaus Abdullah, Asiah Mohd Pilus, Mohd Radzani Abdul Razak, Abu Yazid Abu Bakar, Denise Koh Choon Lian, Mohamad Nizam Nazarudin (2021). The Advantages and Disadvantages of Physical Exercise among Future Engineers and Technologists. International Journal of Human Movement and Sports Sciences, 9(2), 340 - 346. DOI: 10.13189/saj.2021.090223.

Copyright $\bigcirc 2021$ by authors, all rights reserved. Authors agree that this article remains permanently open access under the terms of the Creative Commons Attribution License 4.0 International License

\begin{abstract}
The goal of this paper is to explore perceptions of the advantages and disadvantages of physical exercise, in particular workouts among students at Universiti Teknikal Malaysia Melaka (UTeM). These students must ensure that they are clever and fit if they want to be created to become highly profitable staff who are keen to play their part in the dream of a developed country of world class. Objective: To explore perceived advantages and barriers to physical tasks among students of the Technical University. Method: 355 students from the curriculum courses at Universiti Teknikal Malaysia Melaka (UTeM) completed the EBBS (Exercise Benefits/Barriers Scale). Findings: Physical fitness was the foremost perceived advantage of exercise, accompanying the benefits of cognitive perspective, precautionary well-being, life improvement, and social interaction. Physical output was substantially above the other benefits. There were no major variations in psychological and preventive health outlook, but they are substantially beyond enhanced life and social ties. Also greatly beyond social interaction was the transition to life. Working-out's, slightly higher than time, exercise and family discouragement obstacles were the most perceived obstacles to exercise. The findings of this survey include
\end{abstract}

the significance, for women, of perceiving a good benefit-barrier ratio that is conducive to exercise participation for preparation of physical activities services. In particular, methods must assist students to disengage or monitor physical perception 'delusions' or flowing from perceived during physical operation (reduces their perceived barriers) or to further emphasize the various safety and other wellness advantages. (Increase their perceived benefits).

Keywords Physical Activity, Motivation, Benefits Barriers, Technical University Students

\section{Introduction}

Participation in physical activity as part of free time has become an increasing area of focus in recent years [1]. For you, physical exercise is a healthy thing and should be just one of life's ongoing tasks. By way of a systematic and organized workout or physical exercise, physical well-being can be sustained and enriched so that the individual reduces the stress of life in the management of 
everyday life. The physical activity migration among teenagers is worrying, however. U.S. studies, in effect, have found that in 65 percent of adolescents there may be insufficient physical activity levels in the United States [2].

Although in Australia, this prevalence was proven to be high for adult female subjects predominantly [3]. Studies have also been conducted in adolescents to identify factors that encourage adolescent physical activity in adults. The importance of participation in sport and physical activity has been recognized by scientists and so there has been an increase in research reports in this area. [6-8].

The individual inactivity, including intimate, interpersonal, environmental and legislation, is adequately clarified and implemented. With clear reference to the obstacle element, health conduct [9] is the single strongest indicator, but the barrier to practice has never been seen in detail. [10]. More awareness of advantages and barriers to physical activities will allow medical professionals to help build a way of stimulating the workout of physical and mental health care easier for researchers in college [11].

Since data are not available during theoretical research in the school, this paper aims to evaluate the benefits and barriers developed for MTUN students' participation in physics.The success of this study will aid in developing advocacy practices for physical activity that can encourage the culture for behavioural experience and stamina of young engineers by trying to recommend techniques or ways of promoting particular or general policies.

\section{Materials and Methods}

This is a descriptive study to explore perceived benefits and obstacles to physical activity among UTeM's students. Questionnaires were issued to 355 students from each faculty at UTeM. For data collection, a questionnaire has been handled comprising two sections. The first section discussed demographic data and the next was concerned with the following scale to collect data about perceived physical percentiles and challenges for physical activity.

The EBBS questionnaire [12], previously is used by Saadan [18] consisting of two components: Benefits and Barriers, measured the perceived benefit and barrier strength of the exercise. The advantages section consisted of 29 benefit elements grouped into five sub scales: life change, fitness, psychological outlook, social participation, and preventive health. The barrier section included 14 barrier items divided into four sub scales: fitness environment; time spent; physical exercise; and family discouragement.

\section{Result}

From this study, 355 sets of questionnaires were distributed to UTeM students. The raw data obtained from the demographic questionnaire were analysed using the total number and percentage. Table 1 indicates the co-curriculum course-based distribution of respondents. Of the 355 respondents, a total of 15 (4.2\%) from Co-Curriculum Hockey, 58 (16.3\%) from Co-Curriculum Football, 42 (11.8\%) from Co-Curriculum Health Management, 11 (3.1\%) from Co-Curriculum First Aid and 76 (21.4\%) from Co-Curriculum Red Cross. Meanwhile, 41 (11.5\%) people from the Tahsin Al-Quran Co-Curriculum and 112 (31.5\%) from the Track and Field Co-Curriculum.

The Demographics table also displays the distribution of the respondents using CGPA. In all of these results, 107 individuals had a value of 3.50 to 4.00 (30.1\%), and $174(49.0 \%)$ of CGPA gained from 3.00 and 3.49 to 73 (49.0\%). Although 1 in 0.3 per cent people earn below 2.20 amount of CGPA. Of the 355 participants, 162 (45.6\%) were masculine and the remainder were 193 males.

Table 1. Demographic Characteristic of The Samples

\begin{tabular}{|c|c|c|c|}
\hline & Courses & $\mathbf{N}$ & $\%$ \\
\hline \multirow{7}{*}{$\begin{array}{l}\text { CO-CURRICULUM } \\
\text { COURSES }\end{array}$} & Hockey & 15 & 4.2 \\
\hline & Football & 58 & 16.3 \\
\hline & $\begin{array}{c}\text { Health } \\
\text { Management }\end{array}$ & 42 & 11.8 \\
\hline & First Aid & 11 & 3.1 \\
\hline & Red Cross & 76 & 21.4 \\
\hline & Tahsin Al-Quran & 41 & 11.5 \\
\hline & Track and Field & 112 & 31.5 \\
\hline \multirow{4}{*}{ CGPA } & $3.50-4.00$ & 107 & 30.1 \\
\hline & $3.00-3.49$ & 174 & 49.0 \\
\hline & $2.20-2.99$ & 73 & 20.6 \\
\hline & Below 2.20 & 1 & 0.3 \\
\hline \multirow{2}{*}{ GENDER } & Male & 162 & 45.6 \\
\hline & Female & 193 & 54.4 \\
\hline \multirow{4}{*}{ AGE } & $18-19$ years & 17 & 4.8 \\
\hline & $20-21$ years & 191 & 3.8 \\
\hline & $22-24$ years & 118 & 33.2 \\
\hline & $\begin{array}{c}25 \text { years and } \\
\text { above }\end{array}$ & 29 & 8.2 \\
\hline \multirow{4}{*}{ ACCOMMODATION } & Residence Hall & 242 & 68.2 \\
\hline & Off Campus & 64 & 18.0 \\
\hline & Family Home & 42 & 11.8 \\
\hline & Others & 7 & 2.0 \\
\hline
\end{tabular}

The distribution of respondents based on age can also be seen from the table 1 . The results showed that 17 (4.8\%) people aged 18 and 19 years of age, 191 (53.8\%) were between 20 and 21 years of age and 118 (33.2\%) were between 22 and 24 years of age. Although the majority is 29 (8.2\%) people over the age of 25 years. The results also show that $242(68.2 \%)$ live in the residence hall, 64 (18.0\%) live off campus, 42 (11.8\%) live at home with the family, and 7 (2.0\%) live at home with the family. 
Table 2 provides a descriptive figure for the Life Enhance sub scale. Item Exercise enhances overall body function for me with the highest mean value $(\mathrm{M}=4.16$; $\mathrm{SD}=0.71)$, followed by Item Exercise makes me sleep better at night $(M=4.10 ; S D=0.75)$, Exercise raises my mental alertness $=4.08 ; \mathrm{SD}=0.72$; Exercise improves my self-concept $(M=4.06 ; \mathrm{SD}=0.72)$, followed by Exercise improves the quality of my work with a value $(\mathrm{M}=4.03$; $\mathrm{SD}=0.73)$, Exercise improves my self-concept $(M=4.06$; $\mathrm{SD}=0.72)$. Although the lowest is the exercise item, it allows me to minimize exhaustion with a value $(\mathrm{M}=3.65$;
$\mathrm{SD}=0.74)$

For the sub-scale of physical output. Exercise Item raises my physical fitness level with the highest mean value $(\mathrm{M}=4.30 ; \mathrm{SD}=0.75)$, followed by Exercise Item increases my stamina $(\mathrm{M}=4.28$; $\mathrm{SD}=0.71)$, Exercise increases my muscle power $(\mathrm{M}=4.22$; $\mathrm{SD}=0.76)$; Exercise improves the functioning of my cardiovascular system $(\mathrm{M}=4.20$; $\mathrm{SD}=0.66)$, followed by Exercise Item improves my muscle strength $(\mathrm{M}=4.20$; $\mathrm{SD}=0.69)$. Although the lowest is the item My muscle tone is enhanced with exercise value $(\mathrm{M}=4.00 ; \mathrm{SD}=0.74)$.

Table 2. The Exercise Benefits Scale: Mean and Standard Deviation of Each Questionnaire Item. Perceived Benefits Items

\begin{tabular}{|c|c|c|c|}
\hline Life Enhance Sub-Scale & $\mathbf{N}$ & Mean & S.D. \\
\hline My disposition is improved by exercise & 355 & 3.72 & 0.74 \\
\hline Exercising helps me sleep better at night & 355 & 4.10 & 0.75 \\
\hline Exercise helps me decrease fatigue & 355 & 3.65 & 0.82 \\
\hline Exercising improves my self-concept & 355 & 4.06 & 0.72 \\
\hline Exercising increases my mental alertness & 355 & 4.08 & 0.72 \\
\hline Exercise allows me to carry out normal activities without becoming tired & 355 & 4.00 & 0.73 \\
\hline Exercise improves the quality of my work & 355 & 4.03 & 0.73 \\
\hline Exercise improves overall body functioning for me & 355 & 4.16 & 0.71 \\
\hline Physical Performance Sub-Scale & $\mathbf{N}$ & Mean & S.D. \\
\hline Exercise increases my muscle strength & 355 & 4.22 & 0.76 \\
\hline Exercising increases my level of physical fitness & 355 & 4.30 & 0.75 \\
\hline My muscle tone is improved with exercise & 355 & 4.00 & 0.74 \\
\hline Exercising improves functioning of my cardiovascular system & 355 & 4.20 & 0.66 \\
\hline Exercise increases my stamina & 355 & 4.28 & 0.71 \\
\hline Exercise improves my flexibility & 355 & 4.20 & 0.69 \\
\hline My physical endurance is improved by exercising & 355 & 4.14 & 0.70 \\
\hline Exercise improves the way my body looks & 355 & 4.14 & 0.77 \\
\hline Psychological Outlook Sub-Scale & $\mathbf{N}$ & Mean & S.D. \\
\hline I enjoy exercise & 355 & 4.11 & 0.90 \\
\hline Exercise decreases feelings of stress and tension for me & 355 & 4.28 & 0.80 \\
\hline Exercise improves my mental health & 355 & 4.34 & 0.68 \\
\hline Exercise gives me a sense of personal accomplishment & 355 & 4.08 & 0.75 \\
\hline Exercising makes me feel relaxed & 355 & 4.10 & 0.78 \\
\hline I have improved feelings of well-being from exercise & 355 & 4.05 & 0.69 \\
\hline Social Interaction Sub-Scale & $\mathbf{N}$ & Mean & S.D. \\
\hline Exercising lets me have contact with friends and persons I enjoy & 355 & 4.08 & 0.82 \\
\hline Exercising is a good way for me to meet new people & 355 & 3.99 & 0.85 \\
\hline Exercise is good entertainment for me & 355 & 3.96 & 0.85 \\
\hline Exercising increases my acceptance by others & 355 & 3.82 & 0.83 \\
\hline Preventive Health Sub-Scale & $\mathrm{N}$ & Mean & S.D. \\
\hline I will prevent heart attacks by exercising & 355 & 4.05 & 0.83 \\
\hline Exercising will keep me from having high blood pressure & 355 & 3.88 & 0.96 \\
\hline I will live longer if I exercise & 355 & 3.75 & 0.91 \\
\hline
\end{tabular}


For the Psychological Outlook sub-scale. Item Exercise enhances my mental well-being with the highest mean value $(\mathrm{M}=4.34 ; \mathrm{D}=0.68)$, followed by Exercise Item reduces stress and anxiety for me $(\mathrm{M}=4.28$; $\mathrm{SD}=0.80)$, I enjoy exercise $(\mathrm{M}=4.11 ; \mathrm{SD}=0.90)$, followed by Exercise Item helps me feel comfortable with value $(\mathrm{M}=$ 4.10; $\mathrm{SD}=0.78$ ) and Exercise Item gives me a feeling of personal achievement $(\mathrm{M}=4.08$; $\mathrm{SD}=0.75)$. Although the lowest item is I have enhanced feeling of well-being from exercise with a meaning $(\mathrm{M}=4.05 ; \mathrm{SD}=0.69)$.

For the social interaction sub-scale. Item Exercise lets me have interaction with friends and people I enjoy getting the highest mean value $(\mathrm{M}=4.08$; $\mathrm{SD}=0.82)$, followed by Exercise is a good way for me to meet new people $(\mathrm{M}=3.99 ; \mathrm{SD}=0.85)$ and Exercise is good entertainment for me $(M=3.96 ; S D=0.85)$. Although the lowest item is Exercise, it increases my recognition by others with a benefit $(\mathrm{M}=3.82$; $\mathrm{SD}=0.83)$.

The table 2 displays the descriptive statistics for the Preventive Health sub scale. Item I avoids heart attacks by exercising the highest mean value $(\mathrm{M}=4.05$; $\mathrm{SD}=0.83)$, followed by the exercise item stops me from getting high blood pressure $(\mathrm{M}=3.88$; $\mathrm{SD}=0.96)$ and the lowest point is that I will live longer if I exercise the value $(\mathrm{M}=3.75$; $\mathrm{SD}=0.91$ ).

Table 3 displays the data relevant to a sub-scale of the Exercise Milieu scales. There are too few places for me to exercise to have the highest mean value $(\mathrm{M}=3.24$; $\mathrm{SD}=$ 1.08), followed by exercise facilities that do not have convenient schedules for me $(\mathrm{M}=3.11$; $\mathrm{SD}=0.92)$, places for me to exercise are too far away ( $\mathrm{M}=2.79$; $\mathrm{SD}$ = 1.08), followed by item I am too embarrassed to exercise value $(\mathrm{M}=2.38 ; \mathrm{SD}=1.12)$ and item $\mathrm{I}$ think people in exercise clothes are funny $(\mathrm{M}=2.79$; $\mathrm{SD}=$ 1.08). Although the lowest item costs too much money to use worth $(\mathrm{M}=2.02$; $\mathrm{SD}=0.97)$.

For the time cost sub-scale. It takes too much time for an exercise item to have the highest mean value $(\mathrm{M}=2.68$; $\mathrm{SD}=0.89)$, followed by an exercise item that takes too much time from my family obligations $(\mathrm{M}=2.23$; $\mathrm{SD}=$ $0.96)$ and the lowest is an exercise item that takes too much time from family relationships with value $(\mathrm{M}=2.21$; $\mathrm{SD}=0.91)$. Physical Exercise sub-scale, Item Exercise is hard work for me with the highest mean value $(\mathrm{M}=3.01$; $\mathrm{SD}=1.07)$, accompanied by Exercise tires $(\mathrm{M}=2.95$; $\mathrm{SD}$ $=1.00$ ) and the lowest point is exhaustion by exercise with a value $(\mathrm{M}=2.92 ; \mathrm{SD}=0.95)$.

Table 3 also provides a descriptive figure for the Family Discouragement sub scale. The things of my partner (or significant others) do not promote the exercise of the highest mean value $(\mathrm{M}=2.52$; $\mathrm{SD}=1.03)$ and the lowest is My family members do not encourage me to exercise the same value $(M=2.04$;).

Table 3. The Exercise Barriers Scale: Mean and Standard Deviation of Each Questionnaire Item. Perceived Barriers Items.

\begin{tabular}{|c|c|c|c|}
\hline Exercise milieu sub-scale & $\mathbf{N}$ & Mean & S.D. \\
\hline Places for me to exercise are too far away & 355 & 2.79 & 1.08 \\
\hline I am too embarrassed to exercise & 355 & 2.38 & 1.12 \\
\hline It costs too much money to exercise & 355 & 2.02 & 0.97 \\
\hline Exercise facilities do not have convenient schedules for me & 355 & 3.11 & 0.92 \\
\hline I think people in exercise clothes look funny & 355 & 2.08 & 0.95 \\
\hline There are too few places for me to exercise & 355 & 3.24 & 1.08 \\
\hline Time Expenditure Sub-Scaletime Expenditure Sub-Scale & $\mathbf{N}$ & Mean & S.D. \\
\hline Exercising takes too much of my time & 355 & 2.68 & 0.89 \\
\hline Exercise takes too much time from family relationships & 355 & 2.21 & 0.91 \\
\hline Exercise takes too much time from my family responsibilities & 355 & 2.23 & 0.96 \\
\hline Physical Exertion Sub-Scale & $\mathbf{N}$ & Mean & S.D. \\
\hline Exercise tires me & 355 & 2.95 & 1.00 \\
\hline I am fatigue by exercise & 355 & 2.92 & 0.95 \\
\hline Exercise is hard work for me & 355 & 3.01 & 1.07 \\
\hline Family Discouragement Sub-Scale & $\mathbf{N}$ & Mean & S.D. \\
\hline My spouse (or significant other) does not encourage exercising & 355 & 2.52 & 1.03 \\
\hline My family members do not encourage me to exercise & 355 & 2.04 & 1.02 \\
\hline
\end{tabular}


The table 3 above displays the mean distribution and the standard deviation for the benefit of the exercise sub scales. Subscale Physical Efficiency has the highest mean value $(\mathrm{M}=4.18 ; \mathrm{SD}=1.56)$, followed by subscale Psychological Outlook $(\mathrm{M}=4.16 ; \mathrm{SD}=0.59)$, Life Improvement $(\mathrm{M}=3.97 ; \mathrm{SD}=0.54)$. With sub scale Social Interaction with the value $(\mathrm{M}=3.96$; $\mathrm{SD}=0.67)$ and the lowest is the Preventive Health sub scale with the value $(\mathrm{M}=3.89$; $\mathrm{SD}=0.63)$. Physical Exertion has the highest mean value $(\mathrm{M}=2.96$; $\mathrm{SD}=0.74)$, followed by the Activity Milieu subscale $(\mathrm{M}=2.60 ; \mathrm{SD}=0.64)$ followed by the Time Investment sub scale $(\mathrm{M}=2.37$; SD $=0.69$ ) followed by the Family Discouragement sub scale with the value $(\mathrm{M}=2.28 ; \mathrm{SD}=0.87)$. This argument is shown in the diagram below.

Table 4. Descriptive Statistics for Exercise Benefits and Barriers Scale

\begin{tabular}{cccc}
\hline Exercise Benefits Sub Scale & N & Mean & S.D. \\
\hline Physical performance & 355 & 4.18 & 0.56 \\
Psychological outlook & 355 & 4.16 & 0.59 \\
Life enhancement & 355 & 3.97 & 0.54 \\
Social interaction & 355 & 3.96 & 0.67 \\
Preventive health & 355 & 3.89 & 0.63 \\
\hline Exercise Barriers Sub Scale & $\mathbf{N}$ & Mean & S.D. \\
\hline Physical exertion & 355 & 2.96 & 0.74 \\
Exercise milieu & 355 & 2.60 & 0.64 \\
Time expenditure & 355 & 2.37 & 0.69 \\
Family discouragement & 355 & 2.28 & 0.87 \\
\hline
\end{tabular}

\section{Discussion}

The perceived benefits seemed to be more important in this research than the predictions shown. Matters related to barriers are shown to have low rates. Exercise doesn't only assist you last longer-it causes you to live better. Additionally, to create your heart and muscles stronger and prevent a number of diseases, also can improve your mental, and emotional functioning and increase efficiency, and shut relationships. This study shows that training makes it easier for us to live. It may enhance the overall functioning of the body for practitioners. This is consistent with the study carried out by Akbari Kamrani et al. [13]. Though Geoff, Walid and John [14] said you can use exercise to assist your physical body to have better sleep, but the goal remains to enhance the functioning of your body.

Through his study, Burke and McCarty [15] discovered that, through exercise or physical activity, our fitness level can also be increased. It is connected with the outcomes of this work and that. This argument is also backed by previous studies $(13-14,16)$. Not only would train therapy require aerobic capability and muscle size. The activity will help enhance our emotional and physical fitness and cut down on your waistline, growing your sex life and adding years to your life. But it was not what inspired many people to keep themselves involved. People who do daily training prefer to do this because they get tremendous sense of well-being. Throughout the day we become energetic, sleep more thoroughly at night, have stronger interactions and felt more comfortable and supporting for themselves and their lives. And they also provide reliable care for many chosen mental health conditions. In earlier research of such studies, similar observations are carried out by the Kubayi [17], Burke et al., [15], Geoff, Walid and Parker [14] Kamaria and Mohd Sofian [16] and Akbari Kamrani et al., [13].

Recent results highlight the social benefits of exercise, especially with regard to improved social and psychological well-being, with increased feelings of well-being and trust through social interaction. Some social areas that they encourage are promotion of both family relationships and relationships by other individuals, by enhancing personal abilities and networks, by reducing privacy and loneliness. These studies find out for a social dialogue that the training will help you to get acquainted with our friends, meet new people and give us great fun and also increase your acceptance.

Previous research [13-14,17] was promoted here as well. Exercise may help to reduce strokes, disease of the heart, and cancer of the colon. This can help to treat blood pressure disorder, osteoporosis, and high blood pressure. And people who work out are less often injure. Working more often should help you feel better and keep your body under balance. The report is also endorsed by results from the review and other researchers] Rosli Saadan et al. has established [18] on the basis of a prior analysis, that those outer barriers are documented more relevant than the inner obstacles. Low rates of the issues related to internal obstacles are established. The atmosphere for the activity One external barrier to be part of the practice. One of the reasons for the UTeM student to get interested in physical activity is Certain spaces to exercise. The argument is endorsed by reference to Burke et al., [15]. UTeM student has always understood that exercise takes too big a deal of the time they spend. Such results were also agreed with before past study [14,15,18] but Kamaria and Mohd Sofian [16] note that only men are worried about the time they spend during the success of a sport.

The more challenges exercising faced by students in this research are difficult to do for them to work. When we talk about physical exertion, it means acting our muscles to stay fit in different ways. It is regarded as having this barrier in line with Rosli Saadan et al., [18], Burke and McCarthy, [15] and Akbari Kamrani et al. [13]. Family discomfort for the final challenges perceived by the learners is. For this purpose, the wives (or many others) do not promote to play their exercise. Geoff et al. [14], Rosli Saadan et al., [18] and Akbari Kamrani et al. [13] are acknowledged as confirming these efforts. As we can 
observe from the Table 4, it indicates that the student of UTeM enjoyed the benefit instead of the obstacle towards exercise or physical activity. For them, it's important for all sub scales; physical fitness, psychological outlook, life change, social communication and preventive health. With respect to the challenges such as physical exercise, preparation and period commitment, family neglect only some are concerned.

\section{Conclusion and Recommendation}

If we can equate perceived benefits to perceived obstacles, we know that the student at the UTeM likes to take part in an activity. In other words, during their spare time, they exercise for their own interests like sports and recreation. If we can compare with Kenyan Public University [19], their students is influenced by age, year dan course of the study to participate in physical activity. In term of choices, study [20] also shows that involving in sports is much better rather than doing any physical activities. The UTeM has sampled this study; Our findings do not characterize Malaysian university students in general. It is crucial that future research, intended for major specimens of a sample cup to design National Norm Instruments be carried out for future. Precisely identifying any suspected obstacles would be useful before recommending improvements to promote physical exercise among young people. Given its awareness, especially the benefits of being active in training, the school may be advised not only by campaign or promotion of health to promote a greater healthy lifestyle. Higher learning institutions also need to know what their students are interested in, how to ensure that their sports facilities are capable of attracting them to sports and physical activity. If the administrator can make it a reward system for those who are active in physical activity, it could help the health of the university environment.

\section{Acknowledgements}

We thank our colleagues from Institute of Technology Management and Entrepreneurship, Universiti Teknikal Malaysia Melaka, Faculty of Education, Universiti Kebangsaan Malaysia and Centre for Sports and Exercise Science, University of Malaya \& who provided insight and expertise that greatly assisted the research, although they may not agree with all the interpretations/conclusions of this paper.

\section{REFERENCES}

[1] Henderson, Karla A., and Barbara E. Ainsworth. "Researching leisure and physical activity with women of colour: Issues and emerging questions.” Leisure sciences 23, no. 1 (2001): 21-34.

[2] Center for Disease Control and Prevention. (2006). Youth risk behaviour surveillance - United States, 2005 [Electronic Version]. Morbidity and Mortality Weekly Report, 55. Retrieved May 10, 2006 from http://www.cdc.g ov/mmwrpreview/mmwrhtml/ss5505a1.htm.

[3] Booth, Michael, P. Macaskill, L. McLellan, P. Phongsavan, Anthony D. Okely, John W. Patterson, Jan Wright, Adrian Bauman, and Louise Baur. "NSW schools' fitness and physical activity survey.” (1997).

[4] Anderssen, Norman, and Bente Wold. "Parental and peer influences on leisure-time physical activity in young adolescents." Research quarterly for exercise and sport 63, no. 4 (1992): 341-348.

[5] Sallis, James F., Judith J. Prochaska, and Wendell C. Taylor. "A review of correlates of physical activity of children and adolescents." Medicine and science in sports and exercise 32, no. 5 (2000): 963-975.

[6] Nakazawa, Makoto, Daniel F. Mahony, Daniel C. Funk, and Sumiko Hirakawa. "Segmenting J. League spectators based on length of time as a fan." Sport Marketing Quarterly 8, no. 4 (1999): 55.

[7] Cunningham, George B., and Hyungil Kwon. "The theory of planned behaviour and intentions to attend a sport event." Sport Management Review 6, no. 2 (2003): 127-145.

[8] Trail, G. T., D. F. Anderson, and J. S. Fink. "Examination of gender differences in importance of and satisfaction with venue factors at intercollegiate basketball games." International Sports Journal 6, no. 1 (2002): 51-64.

[9] Janz, Nancy K., and Marshall H. Becker. "The health belief model: A decade later." Health education quarterly 11, no. 1 (1984): 1-47.

[10] Ransdell, Lynda B., Nicole Detling, Kathy Hildebrand, Patrick Lau, Laurie Moyer-Mileur, and Barry Shultz. "Can physical activity interventions change perceived exercise benefits and barriers?" American Journal of Health Studies 19, no. 4 (2004): 195.

[11] Grubbs, Laurie, and Jason Carter. "The relationship of perceived benefits and barriers to reported exercise behaviors in college undergraduates." Family \& Community Health 25, no. 2 (2002): 76-84.

[12] Sechrist, Karen R., Susan Noble Walker, and Nola J. Pender. "Development and psychometric evaluation of the exercise benefits/barriers scale." Research in nursing \& health 10, no. 6 (1987): 357-365.

[13] Kamrani, Ahmad Ali Akbari, Seyed Hojjat Zamani Sani, Zahra Fathire-Zaie, Mahdi Bashiri, and Ebrahim Ahmadi. "The psychometric characteristics of the exercise benefits/barriers scale among Iranian elderly." Iranian journal of public health43, no. 3 (2014): 362.

[14] Lovell, Geoff P., Walid El Ansari, and John K. Parker. "Perceived exercise benefits and barriers of non-exercising female university students in the United Kingdom." International Journal of Environmental Research and Public Health 7, no. 3 (2010): 784-798.

[15] Burke, Eimear, and Bernard McCarthy. "The lifestyle 
behaviours and exercise beliefs of undergraduate student nurses: A descriptive study." Health Education 111, no. 3 (2011): 230-246.

[16] Kamarudin, Kamaria, and Mohd Sofian Omar-Fauzee. "Attitudes toward physical activities among college students." Pakistan journal of psychological research 22, no. 1-2 (2007): 43-54.

[17] Kubayi, N. A., and J. Surujlal. "Perceived Benefits of and Barriers to Exercise Participation among Secondary School Students." Mediterranean Journal of Social Sciences 5, no. 20 (2014): 121.

[18] Saadan, Rosli, Zanariah Jano, Safiah Sidek, and Mohamad Bokhari. "Perceived Barriers In Physical Activities Among
University Students." Journal of Human Capital Development (JHCD) 8, no. 1 (2015): 39-46.

[19] Bailasha N. K , Rintaugu E. G , Kamau J , Mwangi F. M Mucheke C. M , Otieno M. D , "Institutional Based Reasons for Students Non-participation in Physical Activity and Sport Programs in the Kenyan Public Universities," International Journal of Human Movement and Sports Sciences, Vol. 8, No. 1, pp. 17 - 23, (2020). DOI: 10.13189/saj.2020.080102.

[20] Olena Lutsenko , Gregory Lucenko , Maryna Khrolenko , Olesya Mehem , "Defining the Conditions of Forming Students Motivation to Movement Activity," International Journal of Human Movement and Sports Sciences, Vol. 8, No. 4, pp. 117 - 123, 2020. DOI: 10.13189/saj.2020.080403. 